\title{
DESIGN EM JOGO: COCRIAÇÃO, PROTOTIPAGEM E TANGIBILIZAÇÃO DE FUTUROS POSSÍVEIS
}

Raquel Gomes Noronha

Universidade Federal do Maranhão

raquelnoronha79@gmail.com

Luciana Bugarin Caracas

Universidade Federal do Maranhão

I.caracas@uol.com.br

Márcio Soares Guimarães

Universidade Federal do Maranhão

falecommg@gmail.com

\author{
Bruno Serviliano Santos Farias \\ Universidade Federal do Maranhão \\ brunoserviliano@gmail.com \\ Ilmarana Caroline Marques Ribeiro \\ Universidade Federal do Maranhão \\ ribeiroilmarana@gmail.com \\ Larissa de Tássia Gomes Passos de Sá \\ Universidade Federal do Maranhão \\ larag_gomes@hotmail.com
}

Resumo: Neste artigo, visamos a contribuir para a discussão sobre o uso de jogos e a prototipação de cenários como forma de construção coletiva de projetos de design, envolvendo as partes interessadas na questão. Conciliar pontos de vistas muitas vezes discrepantes é um desafio empreendido por quem se dedica a projetar em parceria, considerando as experiências vivenciadas e as cosmovisões dos stakeholders implicados no processo. Apresentaremos estudos de caso em que a teoria sobre jogos, ludicidade, prototipagem, codesign são discutidas à luz das reflexões sobre as atualizações do papel do designer como mediador de processos culturais e tangibilizador de ferramentas de materialização, em parceria com os atores envolvidos em tais questões.

Palavras-chave: Jogos mediativos; codesign; prototipagem; ferramentas; imaginação.

\begin{abstract}
In this paper, we aim to contribute to the discussion on the use of games and prototyping scenarios as a way of collective construction design projects, involving stakeholders. Conciliate often discrepant viewpoints is a challenge undertaken by those who dedicate themselves to design in partnership, considering the experiences and worldviews of stakeholders involved in the process. Present case studies in the theory of games, playfulness, prototyping, codesign, taking under consideration reflections on the designer's role updates as mediator of cultural processes and creator of materialization tools, in partnership with the actors involved in such issues.
\end{abstract}

Key-words: Mediative games; codesign; prototyping; tools; imagination. 


\section{INTRODUÇÃO}

Este artigo visa a contribuir para a discussão sobre o uso de jogos e a prototipação de cenários como forma de construção coletiva de projetos de design, envolvendo as partes interessadas na questão. Conciliar pontos de vistas muitas vezes discrepantes é um desafio empreendido por quem se dedica a projetar em parceria, considerando as experiências vivenciadas e as cosmovisões das partes implicadas no processo.

Para avançarmos nesta discussão, lançaremos mão dos princípios mapeados pelos pesquisadores do CoDesign Research Center | Royal Danish Academy of Fine Arts, que propõem um modelo de inovação em design pautado nas estratégias do Design Anthropology. Denominado DAIM (Design Anthropological Innovation Model), os autores (HALSE et al, 2010) propõem uma metodologia baseada em consultas exploratórias, participação sustentada e prototipagem (op. cit, p.10) para criar cenários e futuros possíveis para determinada questão de design.

Discutiremos o uso de jogos (design games) como estratégia de facilitação e emulação de realidades, com o objetivo de construção de cenários futuros nos quais os atores implicados participam de forma ativa do processo de criação e imaginação de tais futuros. A ideia de projetar cenários é um desafio para esta maneira de pensar: desde o princípio se faz o que geralmente acontece no fim do processo - ensaiar as relações e práticas que se constituem no bojo da criação de um novo artefato. As experiências estrangeiras serviram de bases para a criação de metodologias adequadas ao contexto local, que teremos oportunidade de apresentar neste estudo.

Ezio Manzini argumenta em seu livro Design, when everybody designs (2015) que, cada vez mais, os designers se deparam com situações em que a atividade projetual não é uma habilidade apenas sua. Na contemporaneidade, por diversos fatores, os cidadãos vêm exercendo a sua capacidade projetual e a criatividade, com o intuito de resolver os problemas de suas próprias vidas.

Desta forma, processos de inovação bottom-up, ou seja, aqueles promovidos pelos próprios atores sociais que estão envolvidos nas questões que precisam ser resolvidas, posicionam o designer expert, parafraseando Manzini (2015), em outro lugar, diferente daquele do paradigma funcionalista. Para o autor, o papel do designer expert está em conduzir a cocriação, na atividade de mediação de determinados aspectos e, principalmente, na construção de ferramentas que possam tangibilizar e facilitar os processos de construção de sentido e solução de problemas.

Neste estudo, apresentamos reflexões metodológicas, integrando a teoria e a prática, a partir da conceituação de categorias como jogo, cocriação, prototipagem e a sua aplicação em projetos desenvolvidos pelo Núcleo de Pesquisas em Imagen, Design e Antropologia - NIDA - da Universidade Federal do Maranhão. Entre tais projetos, destaca-se a própria construção de jogos na disciplina de Desenvolvimento de Projeto Gráfico II cujo objetivo era construir uma cartografia sobre questões sociais na cidade de São Luís, envolvendo os diversos discursos que envolvem a problemática urbana; e a aplicação de um jogo como estratégia de briefing entre artesãos, consultores e designers/pesquisadores em uma associação de artesãos da grande ilha, com o objetivo de se delinear a construção de um projeto de pesquisa de inovação em produtos cerâmicos. 


\section{POR QUE JOGAR?}

Definir o que é um jogo pode ser desafiador no que se refere às particularidades e aos pontos de vista envolvidos na questão. Para Costikyan (1994), o jogo é atrelado a uma forma de arte ou cultura, na qual os tomadores de decisão buscam um objetivo através da manipulação das fichas do jogo. Já para Salen e Zimmerman (2012, p.95) "um jogo é um sistema no qual os jogadores se envolvem em um conflito artificial, definido por regras, que resulta em um resultado quantificável". Um jogo formal contém narrativa e sequencialidade; um início e um fim demarcados de maneira explícita ou sutil, de acordo com o caráter lúdico e o contexto em que o jogo está inserido.

A geração de possibilidades, de forma lúdica, proporciona situações em que é possível argumentar "e se fizéssemos desse jeito e não daquele?", e esta é a mola mestra do DAIM, oferecendo um processo de inovação open-ended. O "what if?" trazido pelo DAIM é a possibilidade que o jogo, pela sua ludicidade, pelo seu caráter de "faz-de-conta", nos dá de arriscar, de testar - em ser um protótipo de um projeto que se desenvolverá à medida que vai sendo discutido.

O jogo não é somente feito de regras; é, sobretudo, feito para que o jogador tenha uma experiência do jogar dentro de um determinado contexto. Um dos grandes desafios do designer de jogos, quiçá o maior, é proporcionar um alto nível de envolvimento (imersão) do jogador no ambiente artificialmente construído, através da ludicidade. Segundo o psicólogo J. Barnard Gilmore em Child's Play (GILMORE, 1971, apud SALEN e ZIMMERMAN, 2012, p.24), a interação lúdica se refere às atividades que são acompanhadas por um estado comparativo de prazer, euforia, poder e sentimento de autoiniciativa.

Uma referência clássica que se faz ao jogo e ao seu caráter envolvente é o estudo Um jogo absorvente: notas sobre a briga de galos balinesa, de Clifford Geertz, escrito a partir de uma etnografia do autor em uma aldeia balinesa, da década de 1950. Geertz (1989) observa como a briga de galos é metáfora da sociedade balinesa, e como o próprio galo é a representação dos homens e da masculinidade em Bali, além de ser a briga, a imagem dos conflitos sociais observados pelo antropólogo. A partir do termo melodrama - referente à narrativa psicológica daquela ação, e também ao mundo teatral - as apostas, os símbolos presentes na rinha, a "personalidade dos galos", tudo se converte em reflexão e interpretação sobre aquela sociedade.

O jogo profundo e absorvente, como Geertz caracteriza a briga de galo, é caracterizado por Benthan (BENTHAN, 1931 apud GEERTZ, 1989, p. 198) como tão mais absorvente e profundo, quanto maior for a aposta central; isto não significa que o ganho financeiro com a aposta seja o mais importante; o que importa para absorver a atenção dos participantes no jogo é o empenho psicológico; o que deixa o jogo interessante, nas palavras de Geertz "é o que leva-nos para fora do reino das preocupações formais, para reinos mais amplamente sociológicos e sociopsicológicos, e a uma ideia menos puramente econômica do que significa profundidade no jogo." (GEERTZ, 1989, p.198).

Estar "fora do reino das preocupações formais", portanto, é uma importante característica a considerar na elaboração de um jogo envolvente. Prender a atenção das pessoas é uma preocupação de Brandt et al (2008), quando se elabora um jogo sobre uma questão polêmica que envolve a todos os jogadores. Para os autores, os 
objetivos de um jogo são: dar voz aos usuários; desenvolver representações de design compartilhadas entre usuários e designers; transcender as fronteiras do cotidiano para gerar criatividade e inovação. Referenciam-se em Huizinga (HUIZINGA, 1949 apud BRANDT et al, 2008, p. 54) e no seu conceito de Homo ludens para justificar a prática de jogos como mediadora de situações conflituosas em projetos de design. A ludicidade é caracterizada pelo seu poder criativo na modelagem da cultura.

A essência do jogar, portanto, está na intensidade do jogo e na absorção do jogador; na imersão que acontece pelo aceitar das regras e pela participação voluntária; e o estar momentaneamente fora da vida ordinária, por meio do jogo, "que não é a sério", (BRANDT et al, 2008, p.55) dentro de um tempo-espaço definido.

\section{CODESIGN E AS METÁFORAS TEATRAIS}

Ervin Goffman (2011), sociólogo norte-americano, oferece-nos a reflexão sobre a representação de papéis na vida cotidiana e afirma que, necessariamente, representamos um papel de quem somos perante o outro; e que esta representação varia de acordo com a plateia para quem nos apresentamos.

O uso das metáforas teatrais trazidas por Goffman são amplamente utilizadas na literatura sobre jogos aplicados ao design e seus impactos nas propostas de reimaginar/reinventar futuros. A encenação e a troca de papéis com o outro, mudando a posição dos stakeholders é fundamental para a tomada de consciência sobre as possíveis realidades e proposições de alternativas para as questões que se deseja coprojetar em um jogo.

Gabriel Patrocínio (2015) analisa as bases do que hoje designamos por design participativo apresentando uma escala que percorre a relação entre designers e os sujeitos de sua ação, que vai de uma total dependência epistemológica e tecnológica à autonomia dos sujeitos que, tradicionalmente, recebem projetos de design e passam a serem autores de projetos. Design para | design em | design com | design por são os degraus desta escalada rumo à emancipação dos cidadãos comuns em relação à uma imposição projetual externa (e alheia) às realidades locais. O design com - o codesign diz respeito à participação ativa dos agentes locais com o designer não nativo; as atribuições e responsabilidades são compartilhadas e discutidas, mesmo que a liderança do processo ainda seja unilateral, assumida pelo designer (op.cit. p.70).

Cocriação é uma das prerrogativas para realizar um processo projetual participativo, no qual todos os interlocutores tenham voz e oportunidade para imaginar e criar. O papel do designer é justamente intermediar e articular esses processos: deve ser um tradutor, mediador, transformador (NORONHA, 2010; 2012; MARTINS E SILVA, 2009).

Na contemporaneidade, como afirma Manzini (2015, p.48), todos os processos de design se tornam processos de codesign. Com essa prerrogativa, o autor aborda o processo de fechamento e de abertura do processo criativo; no passado, com a baixa conectividade, os processos tinham início, meio e fim mais determinados, e a atividade do designer expert acontecia entre quatro paredes, "gerando um produto final, em detalhes, pronto para ser produzido e lançado no mercado" (op. cit, p.48). Hoje, essa separação não existe - o processo criativo torna-se mais aberto, o que só pode acontecer em um mundo conectado, e todos são convidados a projetar as suas próprias necessidades. 
Manzini discute também as formas de engajamento do designer profissional (expert designer) na configuração do mundo contemporâneo, que o autor considera como propícia aos comportamentos projetuais, ativos e colaborativos de toda a sociedade. Pautados pela possibilidade de colocar sua capacidade projetual em ação, "designing and redesigning their existence" (MANZINI, 2015, p.1), os cidadãos se lançam cada vez mais em atividades colaborativas e, segundo Manzini, o papel do designer "is to fed and support these individual and collective projects - and thus the social change they may give rise to" (op.cit).

Entre as possibilidades e ressemantizações da atuação do designer, nos cabe a atividade de trazer a materialidade e a possibilidade de tangibilização dos processos de colaboração e ativismo empreendidos pelas comunidades e pelos grupos de cidadãos que se mobilizam para pensar e projetar suas vidas para além dos limites da economia capitalista ocidental, visando a uma nova forma de atuar no mundo em que vivemos, considerando a possibilidade de esgotamento dos recursos naturais do planeta. Segundo Manzini, além de estarem resolvendo os problemas ordinários de suas próprias vidas, os cidadãos engajados em processos de inovação social estão efetivamente lançando as bases para uma nova civilização.

A crise econômica mundial impele as pessoas a repensarem suas formas de lidar com suas próprias vidas e a readaptarem-se, modificando, paulatinamente, suas ideias sobre "wellbeing (and work)" (MANZINI, 2015, p.11).

Desta forma, o projetar a própria vida passa a ser uma prerrogativa, e pode-se questionar o papel do designer profissional, já que, no contexto de inovação aberta e protagonizada pelos próprios cidadãos, leigos e não designers, movidos pela necessidade e pelo desejo de se reposicionarem no mundo, assumem a atividade projetual.

Codesign pode ser caracterizado como um processo extremamente dinâmico, incluindo metodologias de construção de consenso, que emprega atividades criativas e proativas, nas quais o designer experts não se furta de sua cultura projetual e de seu repertório cultural e, finalmente, caracteriza-se pela complexidade em tais atividades, que requerem ferramentas específicas para visualizar ideias e fazê-las tangíveis e protótipos para emular realidades possíveis. Como uma nova atribuição do designer (expert), a construção de ferramentas de mediação torna-se um lugar de encontros, de encenações de papéis e de imaginação de cenários possíveis.

A questão da representação (seja ela simbólica ou gráfica) torna-se a pedra de toque para a construção, a partir da etnografia, da pesquisa engajada e do compartilhamento da atividade projetual, de novos lugares de ação e de reflexão para o designer contemporâneo.

\section{VIVÊNCIAS METODOLÓGICAS PARA A CONSTRUÇÃO DE JOGOS MEDIATIVOS}

Em novembro de 2015 foi realizado na ESDI o workshop Staging Design Anthropological Encounters: Possible Libraries?, ministrado no âmbito da cooperação bilateral firmada entre o LADA/ESDI e o CoDesign Research Center, School of Design, Royal Danish Academy of Fine Arts, com título de "Codesign, citizenship and new forms of participation" e financiamento da Agência Dinamarquesa para Ciência, Tecnologia e Inovação. 
Participar deste momento deixou-nos reflexivos sobre as diferenças entre as realidades sociais da Dinamarca e do Brasil e sobre como a metodologia apresentada na ocasião do workshop e no livro Rehearsing the future (2010), no qual é sistematizada por diversos pesquisadores do CoDe, poderia ser ressemantizada e ganhar cor local. Desta forma, o esforço metodológico aqui empreendido é trazer para uma experiência próxima as abordagens e teorias externas, mesclando-as às vivências empíricas e aos referenciais teóricos da nossa própria bagagem acadêmica. Desta forma, buscamos contribuir para a construção de metodologias participativas e centradas nas especificidades culturais locais e nos saberes considerados informais ou tradicionais.

Entender o contexto no qual a questão a ser discutida acontece é o primeiro passo para a concepção do jogo. No campo do Design Anthropology (DA), emergem as contribuições do campo do Design ao da Antropologia e também o oposto acontece, a fim de que o terceiro e híbrido campo - o do DA - seja a possibilidade de construção, materialização e prática de reflexões teóricas sobre as realidades sociais, culturais e tecnológicas que requerem a atuação de designers e antropólogos em associação.

Referenciando-nos em Otto e Smith (2013), sintetizamos os parâmetros por eles considerados caracterizadores do que é o Design Anthropology e chegamos a uma lista de fatores que norteiam um projeto desta natureza; os jogos mediativos ${ }^{1}$, como constatamos empiricamente nos casos estudados, para serem operacionais, precisam contemplar as seguintes prerrogativas: a temporalidade, seja a projeção de um futuro ou uma viagem ao passado, o movimento temporal constrói como o presente é representado; a relação entre a prática e a teoria, entre a matéria e a forma, é ponto crucial de entendimento cosmológico entre os dois campos do saber; a interpretação da realidade, sabendo-se que esta é uma construção relacional, e não um dado: pensar o campo de pesquisa como campo de ação, no qual se estabelecem as regras, os atores em cena, negociam-se os valores, e projeta-se em coparticipação.

Para a construção deste conhecimento, lançamos mão da etnografia. Em toda a sua complexidade que prevê o longo convívio entre os sujeitos da pesquisa, a observação sistêmica do contexto, as entrevistas e a vivência entre os nativos, a etnografia é condição sine qua non para a prática antropológica e já vem sendo aplicada ao design há aproximadamente quatro décadas, como ferramenta de pesquisa e, nesta metodologia de construção de jogos mediativos, é a etapa inicial para o entendimento da situação a ser tangibilizada.

Discutimos e analisamos teoricamente, em esforços de pesquisa anteriores, este processo de tangibilização, mostrando o percurso de materialização de uma representação coletiva (nível simbólico) em uma representação gráfica (nível icônico/indicial), ou seja, como o imaginário de uma coletividade pode ser interpretado na forma de imagens, com o intermédio de um designer (NORONHA, 2010).

A formação de uma equipe interdisciplinar é outra prerrogativa para o design de jogos mediativos. Trazer os stakeholders e suas visões, num primeiro momento, é fundamental para mapear a complexidade do problema a ser tangibilizado. Os

\footnotetext{
${ }^{1}$ Optamos denominar por jogos mediativos este artefato que tem por objetivo mediar pontos de vista e materializar questões socioculturais que subjazem aos projetos de design na contemporaneidade. Uma tentativa de usar categorias em nosso próprio idioma.
} 
conhecimentos projetuais, especializados e vernaculares, denominados por Manzini como expert design e diffuse design, na tentativa de organizar o que são atividades profissionais, executadas por designers e atividades projetuais intuitivas, fruto da própria pulsão humana em sobreviver, corroboram a construção do contexto de pesquisa e ação.

Nesta etapa inicial, lidamos geralmente com o imaginário, com os anseios, com as expectativas de cada um dos implicados no processo. No âmbito das Ciências Sociais, a categoria representação abarca todos estes sentidos. Representar uma situação consiste em construí-la, por meio de discursos e práticas, a partir dos próprios imaginários e vivências, trazendo a bagagem cultural que é peculiar de cada um e construída a partir do convívio sob determinadas instituições sociais, como família, religião, casamento, afiliação política, entre outras. O que nos dá a noção da ampla gama de significados que estão por trás das representações de cada ator implicado na situação em jogo.

Pensar a construção coletiva de um percurso levou-nos a um mergulho no método cartográfico. Diferentemente do fazer processual, a partir de caminhos preestabelecidos pautados pelas metodologias científicas modernas, a cartografia se dá pelo caminho inverso: é a experimentação de caminhos indefinidos, em princípio, de acordo com cada localidade estudada. Conforme Passos et al (2014), a metodologia moderna passa a ser ressignificada. Com esta proposta de reposicionamento do paradigma científico, o processo de tangibilização das subjetividades torna-se cada vez mais complexo devido às variáveis inéditas próprias de pesquisas em campo que, por vezes, a metodologia formal não consegue abranger.

Tomada de empréstimo da psicologia e da filosofia, a cartografia oferece a possibilidade de se construir, ao longo do caminho, as metas a serem alcançadas o que, muitas vezes, em um projeto de design, faz-se apenas nas etapas iniciais do briefing e na etapa de "pesquisa". O fazer cartográfico lida com subjetividades e "a cartografia é um procedimento ad hoc, a ser construído caso a caso" (KASTRUP e BARROS, 2009, p. 76). É necessário refletir a ação investigativa de maneira não ortodoxa de modo a contemplar e analisar as particularidades de cada território. Assim como o pensamento humano é fluido e espontâneo, o processo de análise desses aspectos também deve seguir o mesmo ritmo, já que não dá para enquadrar em totalidade a essência humana.

A ideia tradicional de metodologia parte de um pressuposto de que há uma meta pré-estabelecida e que há um caminho a ser percorrido para se chegar até ela. Metá-hódos (meta-caminho), no método cartográfico, passa a ser hódos-metá: o caminho é percorrido, experimentado e assumido como atitude e, então, as metas e objetivos vão sendo construídos ao longo da caminhada, de forma coletiva, com o amadurecimento das questões em jogo (PASSOS et al, 2014, p. 10).

O exercício ao qual nos propomos, pode parecer contraditório, já que oferece etapas metodológicas, mas preferimos que fosse interpretado como um relato de experiência. Como foi dito, a etnografia deve conduzir à construção do contexto e a voz dos implicados na questão deve ser o fio condutor. Não é o designer quem diz qual o tempo, qual o espaço, qual o problema a ser debatido - ele, com seu repertório conceitual, teórico e a sua percepção da realidade construída pelos atores (e sim, ele próprio é um ator!) - materializa e tangibiliza uma ferramenta específica para a situação que requer a solução projetual. 
Durante o referido workshop, Halse apresentou um jogo elaborado pelos pesquisadores do CoDe para solucionar os embates que aconteciam em um condomínio em Copenhagen sobre a coleta do lixo. Entre os implicados - moradores, garis, crianças do condomínio, ativistas da reciclagem, a prefeitura - todos estavam à mesa de jogo e, antes disso, os pesquisadores realizaram a pesquisa etnográfica para entender os pontos de vista de cada grupo, as demandas de cada categoria implicada na questão. Tivemos a oportunidade de jogá-lo e simular os pontos de vistas, imaginar possibilidades e encenar futuros possíveis.

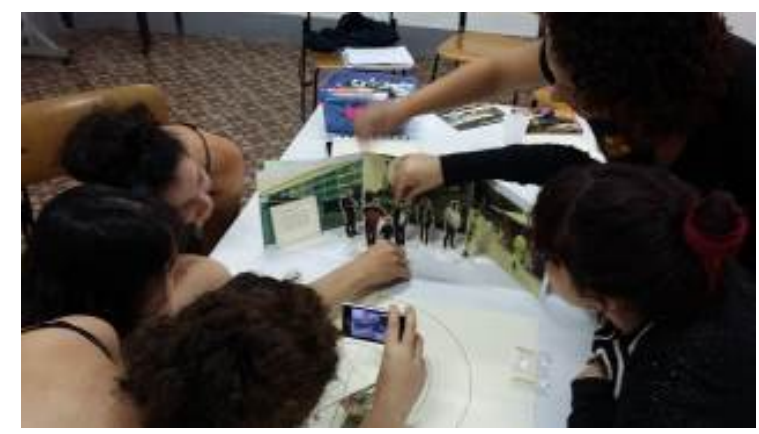

Figura 1 - Participantes do workshop Staging Design Anthropological Encounters, jogando o Rehearsing waste.

Fonte: Fotografia cedida por Joachin Halse, 2015.

Para exemplificarmos melhor as possibilidades e limites do uso de ferramentas de tangibilização de imaginários, apresentaremos dois estudos de caso, nos quais discutiremos o processo de materialização de questões sociais em jogos.

\section{NA MESA DE JOGO}

\subsection{Jogo como ferramenta de criatividade}

A primeira experiência trata-se do uso de jogos como ferramenta de criatividade em projetos de design. A ideia é utilizar os jogos como instrumento de construção de conhecimento para gerar informação, a partir do diálogo entre os implicados na questão.

Os resultados apresentados foram gerados pelos alunos da disciplina de Projeto Gráfico II, do segundo semestre de 2015. Tinham como objetivo traçar cartografias sobre questões sociais e urbanas da cidade de São Luís. O jogo era o resultado de pesquisas, entrevistas, observações sistemáticas nos bairros e percursos dos alunos: violência, empoderamento feminino, questões fundiárias urbanas, coleta seletiva, lixo nas ruas, acessibilidade, indultos aos presos, trânsito entre os bairros foram alguns dos temos escolhidos por cada um.

Durante a fase inicial, os quatro parâmetros que mapeamos sobre o DA foram investigados e organizados, gerando mapas de stakeholders e de situação dos problemas urbanos, realizadas descrições densas utilizando-se o método etnográfico, e análise swot, valendo-se de informações coletadas na mídia, pesquisa de campo (observação sistemática e entrevistas).

De posse destas informações, os alunos foram conduzidos a elaborar seus jogos, levando-se em conta alguns requisitos: existência de regras; duração; uso de tabuleiro, necessidade de gerar perspectivas de futuros. 
Os protótipos foram desenvolvidos e testados. Rodadas de jogos foram organizadas e os alunos foram agrupados de acordo com a semelhança e complementaridade de seus temas. Como seria inviável testar os jogos com os stakeholders de cada projeto, os alunos dos grupos se revezaram nos papéis dos implicados de cada proposta.

Esta situação contingencial foi muito produtiva porque os participantes vivenciaram realmente o "faz-de-conta". A ludicidade gerada por este distanciamento da realidade propiciou embates e soluções inusitadas, oferecendo aos autores de cada jogo a possibilidade de manipular dados complexos em seus resultados finais, as cartografias.

Além destes ganhos, a experiência possibilitou a experiência da prototipagem, o entendimento de que o projeto não termina na primeira proposta e requer burilamento; espírito crítico perante as dificuldades de uma cidade com crescimento desordenado; engajamento e exercício de cidadania.

Abaixo, algumas imagens das rodadas dos jogos e dos tabuleiros. Foram criados, no total, 18 jogos diferentes.

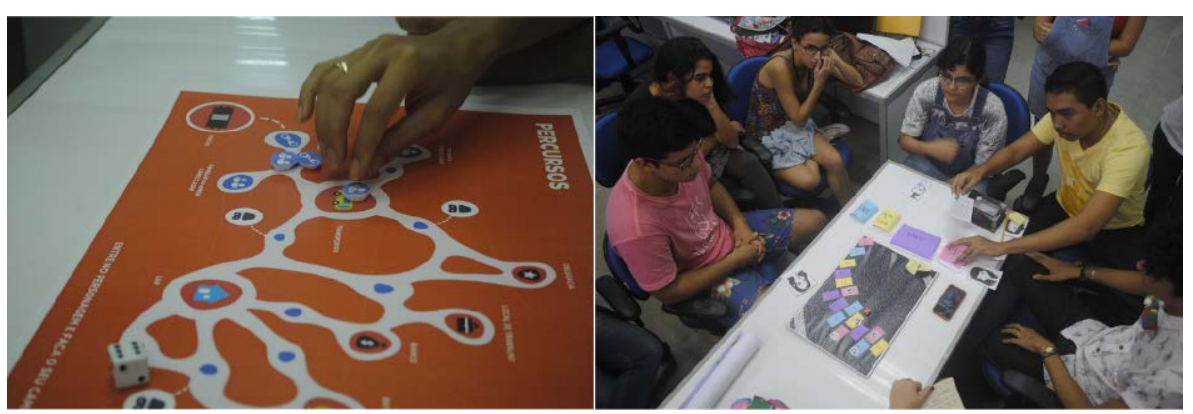

Figura 2 - Jogos na disciplina de Desenvolvimento de Projeto Gráfico II.

Fonte: Acervo dos autores.

\subsection{Associação de artesão de São José de Ribamar: a construção da identidade}

Os diálogos entre as artesãs de São José de Ribamar e a Profa. Luciana Caracas apontavam para a necessidade mútua de trabalharam juntas em um projeto de pesquisa. Contudo, a docente sentia resistência das artesãs em se desapegarem de práticas implantadas ao longo de mais de dez anos de consultorias pelo SEBRAE-MA, o que a impediria de trabalhar de forma mais conceitual, como pretendia. $O$ grupo, que não possuía tradição artesanal autóctone, experimentou durante estes anos de consultoria diversas oficinas e se especializou em cerâmica. O diálogo com a Universidade aconteceu com o intuito de expandirem o portfólio de produtos. Sentindo a necessidade de um processo de intermediação entre os stakeholders da questão, a referida docente, sentindo-se um deles, acionou o NIDA para mediar o processo; avaliamos a questão e sentimo-nos desafiados a propor um jogo, do qual participariam os pesquisadores, bolsistas, artesãs e os consultores que, mesmo com o fim da consultoria pelo SEBRAE-MA há três anos, continuam comprometidos e engajados no desenvolvimento do grupo produtor.

O desenvolvimento do jogo iniciou-se com as visitas à sede do grupo, na qual dois docentes e três bolsistas do NIDA estiveram presentes. As visitas alongaram-se por um mês, e uma entrevista semiestruturada foi realizada com todas as artesãs. 
Houve conversas informais com os dois consultores do SEBRAE e as possibilidades projetuais pretendidas pela Profa. Luciana Caracas foram discutidas com a equipe de projeto.

Ao discutir-se as possibilidades de ação, partiu-se para o desenho do jogo: o que deveria abordar, como abordar, qual seria a dinâmica, que tipo de inquietação poderiam emergir com as provocações que construiríamos em nossas "cartas de jogo". Os quatro parâmetros que vimos utilizando para analisar os projetos do NIDA temporalidade; relação entre teoria e prática; interpretação da realidade; pensar o campo de pesquisa como campo de ação - servem de base para organizar o tabuleiro do jogo. Percebemos, durante a pesquisa de campo, que ambos os lados - artesãs e pesquisadores - estavam preocupados com as perspectivas futuras para o grupo, que começou há poucos anos a caminhar com as próprias pernas. Assim, o presente e o futuro seriam as bases da discussão.

Foi elaborado um tabuleiro simples, em cartolina e algumas imagens coladas, contendo seis estações, sobre os temas mais recorrentes nas entrevistas e conversas que tivemos na sede da associação. Entre os temas propostos, pretendíamos debater: melhorias na comercialização; perspectivas de futuro; sistematização da identidade do grupo; tangibilização da identidade; autoestima; imaginação do turista; gosto pessoal versus o gosto do turista; empoderamento e valor. Essas questões foram organizadas em seis estações relacionadas aos pontos do dado. 1 - gosto; 2 - valor; 3 - processo; 4 - autoestima; 5 - produto; 6 - imaginação. Além do tabuleiro, o jogo constitui-se de cartas de personagens: artesã, consultor e pesquisador; cartas de perguntas: uma série de provocações e questionamentos foi elaborada a partir da etnografia; fichas de "e se...?" que são fichas em branco para serem preenchidas; e no verso do tabuleiro havia o desenho de um alvo.
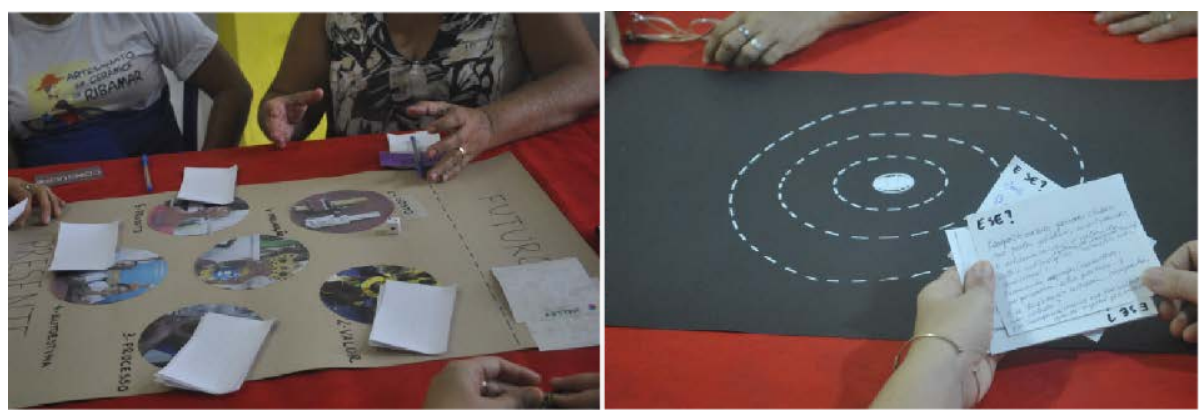

Figura 3-O jogo em movimento: artesãs, consultores e pesquisadores jogando e debatendo as perspectivas futuras da produção artesanal do grupo.

Fonte: Acervo dos autores.

Através de lances de dado, cartas com várias perguntas sobre cada temática e um tabuleiro ilustrativo, o jogo possibilita que os participantes - artesãs, consultores e pesquisadores - simulem uma troca de papéis e, consequentemente, de olhares, sob determinada questão posta no tabuleiro. Um dos objetivos principais do exercício de prototipagem aqui apresentado relaciona-se às possibilidades de soluções e atuação dos protagonistas dentro de seu próprio meio de convívio, no caso, no espaço da associação de artesãos de S. José de Ribamar.

Chegando à sede da associação, parte da equipe de pesquisa, junto aos consultores e as artesãs da comunidade sentam em torno de uma mesa para começar 
a jogar. Cada um sorteia a personagem, e deve responder às perguntas por meio daquele ponto de vista. Na primeira rodada, a pessoa lança o dado e ela própria responde à pergunta do cartão; a rodada acaba quando todos os participantes respondem a uma pergunta. Já na segunda rodada, as pessoas mudam de personagem, por meio de sorteio, e assumem novos papéis. Uma pessoa escolhe quem responderá à pergunta, após o lance de dados.

Ao término de cada lance, cada implicado é convidado a escrever suas propostas para cada questão discutida nas fichas de "e se...?". Ao final de todas as rodadas o tabuleiro é virado e estas fichas são hierarquizadas no alvo, tomando-se em conta a possibilidade de realização das propostas e se contempla a possibilidade de acordo entre cada ator.

Nesta experiência, chamou-nos a atenção a duração do jogo: três horas e meia. As pessoas estavam claramente compenetradas e envolvidas. A ação de projetar um jogo sugere que haja um exame minucioso em todo o processo do jogar e interagir ludicamente com o intuito de antever a experiência por parte do jogador ou jogadores. Durante o processo de elaboração do jogo, foram testadas as possibilidades de variação e tentou-se prever os problemas e percalços do caminho.

Contudo, foi na prática, com os interlocutores reais, que percebemos as falhas e as possibilidades de melhorias. Salen e Zimmerman conceituam design iterativo como "um processo cíclico que se alterna entre protótipos, testes, avaliação e refinamento." (SALEN e ZIMMERMAN, 2012, p. 27). A materialidade do jogo, trazendo imagens, perguntas, criando embates e possíveis cenários, assim como o caráter provisório do tabuleiro, que poderia ser modificado naquele momento, se houvesse possibilidade, traz à tona a ideia de protótipo. Prototipar lida com maneiras de construir, visualizar e experimentar cenários de pontos de vista de interlocutores de um determinado local. É uma forma de imergir em uma determinada realidade ou situação para compreender. Para isso, a colaboração participativa dos stakeholders torna-se decisiva e relevante em relação à inovação.

No início do jogo, houve uma dificuldade de se colocar no lugar do outro, principalmente por parte das artesãs, por timidez e constrangimento, mas também por realmente não se deslocarem de seus posicionamentos. Entre as questões debatidas, a identidade dos produtos, a geração de renda, a preocupação com o gosto do turista foram bastante aludidas.

As artesãs sentiram-se mais à vontade em se engajarem em um projeto de colaboração com a Universidade, percebendo o aval simbólico dos consultores que as acompanham há anos; havia uma preocupação da parte destes que as experiências e intervenções de um projeto de pesquisa pudessem "deturpar" a identidade local. Isso ficou esclarecido e o grupo de pesquisadores ficou mais atento a essa premissa. Houve questões sobre o processo produtivo que são entraves ã melhoria do produto, mas que, naquele momento, ficou claro que não eram percebidos como tão graves aos produtos pelas artesãs, e que isso era, de fato, uma preocupação dos pesquisadores.

Na mesa de jogo, portanto, firmam-se acordos, percebem-se e delimitam-se as questões polêmicas, avais simbólicos são concedidos. Essas percepções e aprendizados foram os frutos colhidos durante aquela rodada. 


\section{GAME OVER}

O esforço deste artigo foi o de mapear e identificar metodologias e experiências projetuais dentro e além do campo do design que possam contribuir para a construção de ferramentas e protótipos que facilitem os projetos em parceria. 0 papel do designer se deslocou da posição modernista de construção de artefatos acabados e ele vem sendo paulatinamente reposicionado como um mediador de processos culturais e tangibilizador de contextos de disputas ideológicas e discursivas.

Os jogos mediativos oferecem a possibilidade, no campo do design, de dar voz ao outro, já amplamente difundida a partir das ideias de relativizar, de estranhar o que é familiar e familiarizar-se com o que é estranho, nas ciências sociais. O conceito de protótipo, como algo aberto, sempre em construção, é metáfora de um texto construído por muitas mãos, e que não se limita a emular algo pronto. A definição de metas e objetivos, assim como a prototipação pode acontecer em qualquer ponto da construção do conhecimento ou de um artefato.

As práticas, é sabido, atualizam-se mais rapidamente que os discursos institucionais ou acadêmicos. A atividade mudou, mas os discursos que embasam a prática projetual, principalmente no âmbito acadêmico, ainda precisam ser revistos. Projetos que lidam com a questão da interdisciplinaridade e que trazem o design para o âmbito das ciências sociais ainda são mal interpretados, por exemplo, nas agências de fomento, que estratificam o conhecimento em blocos estanques. A construção de jogos também não poderia fazer parte de um projeto antropológico? Ou do campo da psicologia? Como avaliar projetos e inscrever resultados na plataforma Lattes, para além das patentes de produtos, que contemplem a construção conceitual de ideias ou serviços? Como medir impactos de projetos que não possuam resultados palpáveis e materiais, registrados em números, tabelas, público-alvo definido a priori, mas trabalham questões como autoestima e empoderamento? Como falar em metas e objetivos, se é ao longo do caminho metodológico que tais elementos deverão se constituir? Como percebemos, há mais inquietações do que respostas.

O campo crescente do design anthropology é espaço de experimentações destes intercâmbios epistemológicos. Questionar os limites dos campos e dos fazeres, assim como a tomada de empréstimos das ferramentas e habilidades de um e outro é enriquecedor no sentido em que elas mesmas não são apenas instrumentos e habilidades profissionais, mas fazem parte da criatividade e da imaginação humanas.

\section{REFERÊNCIAS}

BRANDT, Eva et al. Formating Design Dialogues - Games and Participation. In: BINDER, T; BRANDT, E; GREGORY, J. (guest editors). CoDesign - International Journal of CoCreation in Design and the Arts, Volume 4, Number 1, pp. 51-64. Taylor \& Francis. March, 2008.

GEERTZ, Clifford. A interpretação das culturas. Rio de Janeiro: LTC, 1989.

GOFFMAN, Erving. A representação do eu na vida cotidiana. Petrópolis, Ed. Vozes, 2011.

GUNN, Wendy; OTTO, Ton; SMITH, Rachel Charlotte (eds). Design anthropology: theory and practice. London, New York: Bloomsbury, 2013. 
HALSE, Joachin; BRANDT, Eva; CLARK, Brendon; BINDER, Thomas. Rehearsing the future. The Danish Design School Press: Copenhagen, 2010.

KASTRUP, Virgínia; BARROS, Regina Benevides de. Movimentos-funções do dispositivo na prática da cartografia. In: PASSOS, Eduardo; KASTRUP, Virgínia; ESCÓSSIA, Liliana de. Pistas do método da cartografia: pesquisa-intervenção e produção de subjetividade. Porto Alegre: Sulina, 2014. 207 p.

MANZINI, Ezio. Design, when everybody designs. An introduction to Design for Social Innovation. The MIT Press: Cambridge/London, 2015.

MARTINS, Fernanda O.; SILVA, Sâmia. Identidade \& Sustentabilidade: a abordagem participativa em design como ferramenta de reflexão sobre a Identidade de associações de base comunitária. Disponível em: <http://livrozilla.com/doc/1650941 /identidade-and-sustentabilidade--a-abordagem-participativa-em>. Data de acesso: 05/04/2016.

NORONHA, R. Do centro ao meio: um novo lugar para o designer. São Luís: Anais do P\&D, 2012.

. O designer e a produção de sentido na construção de iconografias. In:

BRASIL, R. (org). A imagem na idade mídia. São Luís, EDUFMA: 2010.

PASSOS, Eduardo; KASTRUP, Virgínia; ESCÓSSIA, Liliana de. Pistas do método da cartografia: pesquisa-intervenção e produção de subjetividade. Porto Alegre: Sulina, 2014. 207 p.

PATROCÍNIO, Gabriel. Design e os países em desenvolvimento: a dialética entre o design para a necessidade e o design para o desenvolvimento. In: PATROCÍNIO, Gabriel; NUNES, José Mauro. Design e desenvolvimento 40 anos depois. São Paulo: Blucher, 2015.

SALEN, Katie; ZIMMERMAN, Eric. Regras do jogo: fundamentos do design de jogos: principais conceitos. v. 1. São Paulo: Blucher, 2012. 